\title{
IDENTIFIKASI DAMPAK DECK WATER SEAL UNTUK PENINGKATAN KERJA INERT GAS SYSTEM DI MT. GREEN STARS DENGAN METODE FTA
}

\author{
Wahyu Aji ${ }^{a}$, Jamiul Alimb dan Sri Purwantinic \\ Taruna (NIT. 49124675.T) Program Studi Teknika PIP Semarang \\ ${ }^{\mathrm{b}}$ Dosen Program Studi Teknika PIP Semarang \\ ${ }^{\mathrm{c}}$ Dosen Program Studi KALK PIP Semarang
}

\begin{abstract}
ABSTRAK
Inert Gas System adalah pesawat bantu yang digunakan untuk mempertahankan kadar oksigen yang rendah dalam tangki sehingga memungkinkan timbulnya kebakaran. Purging pada tangki-tangki muatan yang kosong dengan maksud menggantikan campuran hidrokarbon gas dengan inert gas agar bisa mengurangi konsentrasi atau kadar hidrokarbon di bawah garis yang disebut Critical Dilution. Kalau sampai ada udara segar masuk ke dalam tangki tersebut maka kondisi atmosfir dalam tangki akan segera masuk dalam kantong dimana campuran ini dapat terbakar atau rusak. Terdapat 3 permasalahan yang terdapat pada IGS saat dioperasikan yaitu perawatan Deck Water Seal diperlukan dalam pengoperasian IGS, dampak apabila Deck Water Seal tidak bekerja secara maksimal dan upaya yang dilakukan agar Deck Water Seal bekerja secara maksimal dalam pengoperasian IGS.

Untuk mengupayakan agar IGS dapat beroperasi dengan maksimal maka diadakan penanganan yang baik dan tepat, dalam mencari solusi permasalahan digunakan metode Fault Tree Analysis (FTA). Metode analisis ini terutama digunakan dalam bidang teknik keselamatan dan rekayasa keandalan untuk memahami bagaimana sistem bisa gagal, untuk mengidentifikasi cara terbaik untuk mengurangi resiko angka kejadian kecelakaan keselamatan atau system fungsional, FTA mengidentifikasi hubungan antara faktor penyebab dan ditampilkan dalam bentuk pohon kesalahan yang melibatkan suatu gerbang logika sederhana. Perawatan Deck Water Seal sangat penting dalam pengoperasian IGS, yaitu salah satunya merawat komponen yang menunjang kinerja dari Deck Water Seal seperti demister pad, inert gas blower. Dalam demister pad ada komponen lain yaitu deck seal pump dan drain valve. Begitu juga dalan iner gas blower ada safety valve, mast riser, non return valve. Komponen tersebut sangatlah penting guna menunjang kinerja dari deck water seal. Masinis dapat melaksanakan kegiatan perawatan dengan baik terhadap deck water seal, agar kerja dari deck water seal dapat bekerja secara maksimal pada saat pengoperasian IGS di kapal.
\end{abstract}

Kata kunci : inert gas system, metode fault tree analysis, perawatan deck water seal

\section{PENDAHULUAN}

Kebutuhan jasa angkutan pelayaran dari tahun ke tahun mengalami peningkatan yang sangat pesat, khususnya kapal niaga. Kapal niaga sebagai sarana transportasi air yang mempunyai peranan sangat penting dan efisien dalam pengangkutan dari satu tempat ke tempat tujuan, salah satunya adalah kapal tanker atau kapal muatan minyak yaitu kapal yang mempunyai fungsi untuk mengangkut muatan minyak mentah maupun minyak hasil olahan atau product dalam bentuk curah melalui jalur laut atau jalur perairan dari pelabuhan muat ke pelabuhan bongkar. Berbicara tentang minyak tentu erat kaitannya dengan bahaya yang bisa terjadi sewaktu-waktu, dalam hal 
ini adalah gangguan keselamatan pada saat penanganan muatan di atas kapal yang berdampak pada pencemaran lingkungan. Melihat dari konstruksinya yang khusus yaitu kapal dengan tangki berisi minyak maupun gas baik minyak mentah, bahan kimia dan minyak hasil olahan. Maka dalam membangun kapal disesuaikan dengan sifat muatan yang akan dibawa oleh kapal. Terutama kapal yang mengangkut muatan minyak bumi atau dari hasil pengolahan, karena sifat dari muatan tersebut memiliki karakteristik yang mudah menyala hal ini disebabkan karena terbentuknya gas hasil penguapan yang terus-menerus. Menyadari dan mengetahui akan pentingnya peranan sistem gas lembam di kapal-kapal tanker sebagai suatu sistem keselamatan yang dapat mengurangi resiko kecelakaan, baik kebakaran, ledakan maupun toxic (racun) yang ditimbulkan pada saat pengoperasian kapal, maka dari itu penggunaan dari sistem ini ditekankan dalam SOLAS Convention 1974 (Regulation 62:II-2), dan peraturan serta kegunaan sistem ini disempurnakan lagi dalam konferensi international di London mengenai Tanker Safety and Pollution prevention / TSPP Protocol 1978. Tambahan baru Regulation 62 (a) mensyaratkan bahwa Inert Gas System (IGS) harus direncanakan, dibangun dan diperiksa sesuai ketentuan dan memenuhi peraturan IMO. Dalam hal ini pemerintah adalah anggota IMO dimana kapal tersebut diregistrasikan. Salah satu komponen yang ada dalam IGS yaitu Deck Water Seal.

Deck Water Seal dapat berfungsi untuk mencegah jangan sampai terjadi aliran balik (backflow) dari gas hidrokarbon (cargo gas) dari tanki muatan ke daerah yang seharusnya bebas gas (safe area) di mana alat Inert Gas terpasang (Batti,1983:55). Sisa gas dalam tangki muatan harus dilembamkan, adapun data muatan yang tingkat bahayanya dapat dilihat pada lampiran. Gas inert digunakan pada kapal gas untuk mempertahankan tekanan positif pada tangki muatan dan ruang inter barrier. Inert gas dioperasikan sesuai ketentuan untuk mencegah terjadinya kebakaran. Pada tangki muatan operasi gas lembam sangat dibutuhkan untuk aerasi pada saat pemeriksaan dan drydock, tetapi operasi tersebut akan memakan waktu, inerting juga dibutuhkan sebelum loading dari kondisi free gas. Berkaitan dengan inertinglevel diharuskan untuk gassing up, kadar oksigen dalam tangki muatan harus kurang dari $5 \%$, tergantung permintaan loading terminals. Sebelum aerasi, proses inerting harus mencapai kadar hidrokarbon di bawah $2 \%$. Sulphur Dioxide (SO2) harus dapat dikeluarkan dari inert gas paling kurang $90 \%$, karena gas ini larut dalam air maka untuk mengeluarkannya flue gas dari Boiler dialirkan melalui air sambil mendinginkan atau menurunkan temperatur dari flue gas tersebut. $\mathrm{SO} 2+\mathrm{H} 2 \mathrm{O}-\mathrm{H} 2 \mathrm{SO} 3$ sifatnya korosi dapat dikeluarkan bersama-sama air pencuci tadi (effluente) agar dapat menghambat adanya pengendapan pada pipa inert gas yang terbawa bersamaan dengan air pencuci tersebut.

Namun demikian dari fakta yang terjadi di atas kapal masih terjadi beberapa permasalahan pada Deck Water Seal seperti demister pad, inert gas blower. Selain demister pad ada komponen lain yaitu deck seal pump dan sea chest. Begitu juga dalan iner gas blower ada safety valve, mast riser, non return valve. Komponen tersebut sangatlah penting guna menunjang kinerja dari deck water seal. Adapun yang menyebabkan kegagalan dari Deck Water Seal yaitu terjadinya trouble dari tiap-tiap komponen yang membangun Deck Water Seal . Adapun komponen-komponen yang mengakibatkan kegagalan fungsi dari Deck Water Seal apabila mengalami masalah diantaranya adalah Srubber system tidak bekerja normal, kadar oksigen dalam system tinggi. Dan komponen yang menunjang kinerja dari deck water seal yaitu demister pad, safety valve, drain valve, overboard valve, sight glass, non return valve. Dari komponen di atas apabila salah satu terjadi masalah maka akan berdampak pada kinerja Deck Water Seal.

Berdasarkan wawancara dengan Masinis I bahwa dampak dari tidak normalnya deck 
water seal adalah terjadi aliran balik (back flow) dari gas hidrokarbon (cargo gas) dari tangki muatan ke daerah yang seharusnya bebas gas (safe area) dimana alat inert gas terpasang. Karena bila gas yang dari tangki kembali kedalam area yang bebas gas bisa mengakibatkan ledakan yang hebat didalam IGS, maka dri itu sangatlah penting IGS dalam proses bongkar muat di tas kapal. Berdasarkan hasil penelitian dengan studi pustaka, diperoleh beberapa dokumen sebagai sarana pendukung dari skripsi ini. Dari dokumen yang didapat diantaranya data kejadian tidak normalnya Deck Water Seal dalam menunjang kinerja dari IGS.

Tujuan penelitian ini adalah untuk mengetahui dampak yang terjadi apabila Deck Water Seal tidak bekerja secara maksimal guna menunjang kinerja IGS. Selanjutnya dengan metode Fault Tree Analysis didapatkan ranking dari yang tertinggi sampai yang terendah dari dampak yang terjadi apabila Deck Water Seal tidak bekerja secara maksimal, kemudian dilaksanakan penelitian Penulis selama melaksanakan praktek laut.

\section{Waktu dan Tempat Penelitian}

Penelitian dilaksanakan di atas kapal MT. Green Stars, yang dimiliki oleh perusahaan PT. Waruna Nusa Sentana yang berkantor di Plaza Pasifik, Blok B2 No. 29-35 Jalan Boulevard Barat Raya, Kelapa Gading Jakarta. Kapal ini berjenis kapal tanker double hull oil tanker esp, LI, IWS + LMC, UMC, IGS, dibuat pada tanggal 25 September tahun 2000, oleh Daedong Ship Yard, South Korea. Kapal berbendera Indonesia, DWT 36,876 ton, LOA 183,00 meter, LBP 175,17 meter, dengan $\mathrm{ME}$ Wartsila Sulzer 6 RTA 48T, N.C.R $(85 \%$ MCR) 9435 BHP x 120,3 RPM, Speed 13,5 (ballast) \& 13,0 (loaded), 11100 BHP.

Rute pelayaran kapal memiliki route liner, yang berarti pelayaran yang tetap. Penelitian dilakukan sacara langsung pada saat kapal manuever dari Ardjuna Marine Terminal menuju pelabuhan pangkalan susu, Sumatera. Peneliti berusaha mencari dan mengumpulkan data nyata dari lapangan yang kemudian diolah menjadi bahan penelitian. Waktu penelitian dilakukan selama tiga belas bulan ketika Penulis melakukan Praktek Laut, yaitu terhitung mulai 06 November 2014 sampai dengan tanggal 06 Desember 2015.

\section{METODE PENELITIAN}

Data yang didapat dari hasil penelitian yang mencakup pengamatan, wawancara dan dokumentasi yaitu dalam bentuk katakata, termasuk kutipan-kutipan atau deskripsi peristiwa-peristiwa khusus mengenai objek penelitian. Dalam hal ini untuk mengkaji hasil penelitian, Penulis menggunakan metode penelitian kualitatif dan data yang digunakan yaitu dalam bentuk teks, kata-kata tertulis, frase-frase atau simbol yang mendeskripsikan atau mepresentasikan tindakan-tindakan, dan peristiwa-peristiwa yang terjadi dalam objek penelitian. Prosedur analisis penelitian kualitatif mengacu pada prosedur analisis nonmatematis yang hasil temuannya diperoleh dari data yang dihimpun oleh ragam alat. Alat yang digunakan sebagai teknik analisis dalam penelitian ini yaitu Fault Tree Analysis (FTA). FTA adalah analisa kegagalan deduktif dimana keadaan yang tidak diinginkan dari sistem dianalisis menggunakan logika Boolean untuk menggabungkan serangkaian tingkat yang lebih rendah. Metode analisis ini terutama digunakan dalam bidang teknik keselamatan dan rekayasa keandalan untuk memahami bagaimana sistem bisa gagal, untuk mengidentifikasi cara terbaik untuk mengurangi resiko angka kejadian kecelakaan keselamatan atau sistem fungsional. FTA digunakan pada penelitian di ruang angkasa, tenaga nuklir, kimia dan proses farmasi, petrokimia dan identifikasi faktor resiko yang berkaitan dengan kegagalan sistem yang ada.

Metode FTA juga merupakan suatu teknik yang digunakan untuk mengidentifikasi suatu resiko yang berperan langsung terhadap terjadinya kegagalan. FTA mengidentifikasi hubungan antara 
faktor penyebab dan ditampilkan dalam bentuk pohon kesalahan yang melibatkan suatu gerbang logika sederhana. Gerbang logika berfungsi untuk menggambarkan kondisi yang memicu terjadinya kegagalan,baik kondisi tunggal maupun sekumpulan dari berbagai macam kondisi. Dalam pembahasan suatu masalah dengan menggunakan metode fault tree analysis memerlukan suatu diagram yang disebut pohon kesalahan, dimana metode ini ada beberapa simbol yaitu basic event, top event, kemudian akan menghasilkan cut set, dalam penyusunan diagram ini akan menghasilkan basic event. Basic event adalah kegagalan mendasar yang tidak perlu dicari penyebabnya yang merupakan batas akhir penyebab suatu kejadian.

\section{HASIL PENELITIAN DAN DISKUSI}

Dalam pembahasan suatu masalah yang menyebabkan dampak dari kinerja deck water seal pada saat pengoperasian IGS, Penulis menganalisa data yang didapati pada saat melaksanakan pengamatan terhadap Deck Water Seal dengan menggunakan metode fault tree analysis. Sebelum membahas tentang permasalahan dampak yang mengakibatkan kerusakan bagian Deck Water Seal, terlebih dahulu menentukan akibat utama dari permasalahan tersebut. Dalam mencari pokok permasalahan Penulis menganalisa penyebab yang mungkin terjadi pada Deck Water Seal selama Penulis melakukan pengamatan. Pertama yang dilakukan yaitu membuat kerangka diagram fault tree analysis (Gambar 3). Kerangka diagram fault tree analysis meliputi basic event, top event, kemudian akan menghasilkan cut set. Basic event disimbolkan seperti lingkaran, symbol ini digunakan untuk menyatakan basic event atau primery event atau kegagalan mendasar yang tidak perlu dicari penyebabnya. Keduanya saling berhubungan denga pohon kesalahan yang sebelumnya telah di buat ini nantinya digunakan untuk menyatakan masalah utama. Top event disimbolkan seperti persegi panjang, simbol ini berisi kejadian yang muncul dari kombinasi kejadian input gagal yang masuk ke gerbang. Cut set yaitu hasil yang diperoleh dari pengujian masing intermediate event sampai basic event untuk memperoleh penyebab dari top event. Dengan adanya FTA ini Penulis dapat mengetahui dampak yang terjadi pada deck water seal. Dengan melakukan analisa kualitatif menggunakan pendekatan fault tree analysis, maka dapat diketahui bagian mana dari system yang mengalami penurunan kualitas operasi dan perlu dilakukan tindakan perawatan serta perbaikan agar kejadian yang sama tidak terulang kembali. Selanjutnya menyepakati pernyataan masalah, setelah menemukan permasalahan pada Deck Water Seal, penjabaran pohon kesalahan (Gambar 4) dari top event pertama adalah merawat demister pad pada IGS. Demister pad pada IGS harus selalu diperhatikan dengan teliti karena sangatlah penting peran demister pad pada IGS yaitu untuk penyaring gas yang sudah dicuci dan didinginkan di Scrubber masuk ke demister dimana ada sisa-sisa partikel dan liquid terutama air.

Dampak yang terjadi apabila deck water seal tidak bekerja secara maksimal akan menimbulkan gangguan pada IGS dan komponen deck water seal maupun IGS. Dengan rusaknya komponen, mesin yang ada maka akan berpengaruh pada kinerja dari deck water seal. Dampak selanjutnya yang akan terjadi apabila deck water seal tidak bekerja secara maksimal yaitu naiknya suhu gas lembam. Naiknya suhu gas lembam mengakibatkan IGS akan shut down atau trip apabila gangguan yang tersebut diatas terjadi saat sistem inert gas sedang beroperasi, dan hal tersebut akan dapat berakibat pada matinya pompa kargo. Kemudian dampak yang terjadi yaitu terjadinya aliran balik gas hidrokarbon dari tangki muatan kembali ke area yang seharusnya bebas gas. Dari data tersebut dapat dijabarkan menggunakan aljabar boleean menggunakan gerbang logika Or, karena dari masing-masing basic event tidak saling mempengaruhi dan tidak saling 
terjadi. Bila basic event tidak terjadi maka top event tidak terjadi. Hasil analisa kualitatif yang didapat dari identifikasi dampak yang terjadi apabila deck water seal tidak bekerja secara maksimal dalam pengoperasian IGS dengan top event yaitu optimalisasi kinerja deck water seal dalam pengoperasian IGS pada deck water seal, didapat beberapa hasil dari penjabaran yang dilakukan seperti penjelasan di atas.

Kemudian setelah didapatkan hasil kualitatif maka selanjutnya melakukan perawatan terhadap deck water seal, yaitu dengan sistem perawatan terencana (planned maintenance system). Planned maintenance system terdiri dari banyak elemen seperti perencanaan, pelaksanaan kerja, pencatatan dan evaluasi. Tujuan dari sistem ini adalah menyusun rencana dan operasional kerja di atas kapal yang sudah ditetapkan oleh perusahaan yang bertanggung jawab atas manajemen operasional dan berdasarkan ISM (Intetnational Safety Management). Sistem ini dapat memberikan kesinambungan perawatan, sehingga masinis di atas kapal dapat melaksanakan program perawatan yang tidak tumpang tindih. Selain itu, pengorganisasian pekerjaan yang telah dikelompokan akan memudahkan terjadinya proses perawatan perbaikan. Empat langkah dasar perawatan yang sesuai dengan manajemen perawatan yaitu perencanaan, pelaksanaan kerja, pencatatan dan pelaporan, kemudian bisa di evaluasi dan direvisi.

\section{KESIMPULAN}

Dampak yang terjadi apabila deck water seal tidak bekerja secara maksimal yaitu naiknya suhu gas lembam pada tangki muatan, dimana apabila suhu gas dalam tangki tinggi maka bisa mengakibatkan kebakaran dan ledakan, dampak selanjutnya akan terjadinya aliran balik gas hidrokarbon dari tangki muatan kembali ke area yang seharusnya bebas gas.

\section{DAFTAR PUSTAKA}

$\begin{array}{ll}\text { Badan Diklat Perhubungan. Oil } & \text { Tanker } \\ \text { Familiarization. } & \text { Tanker } \\ \text { Familiarization Cource } & \text { (TFC). } \\ \text { Modul-1 (Cetakan Pertama } & \text { Maret } \\ \text { 2000). Jakarta } & \end{array}$ - Crude Oil Washing. Oil Tanker Training (OTT), Modul-2 (Cetakan Pertama Maret, 2000). Jakarta

Inert Gas System. Oil Tanker Training (OTT) Modul -3 (Cetakan Pertama Maret 2000). Jakarta

Ibrahim. 2015. Metodologi Penelitian Kualitatif. Bandung : Alfabeta

IMO. 1990. Inert Gas System. London

Inert Gas System. KHASIWA Marine, (Instruction Manual Book MT. GREEN STARS)

Kristiansen, Svein. 2004. Maritime Transportation Safety Management Risk Analysis Book aid International. New York

McGUIRE and White. 2000. Liquid Gas Handling Principles On Ships And In Terminals. Third Edition. London : Witherby \& Company Limited 


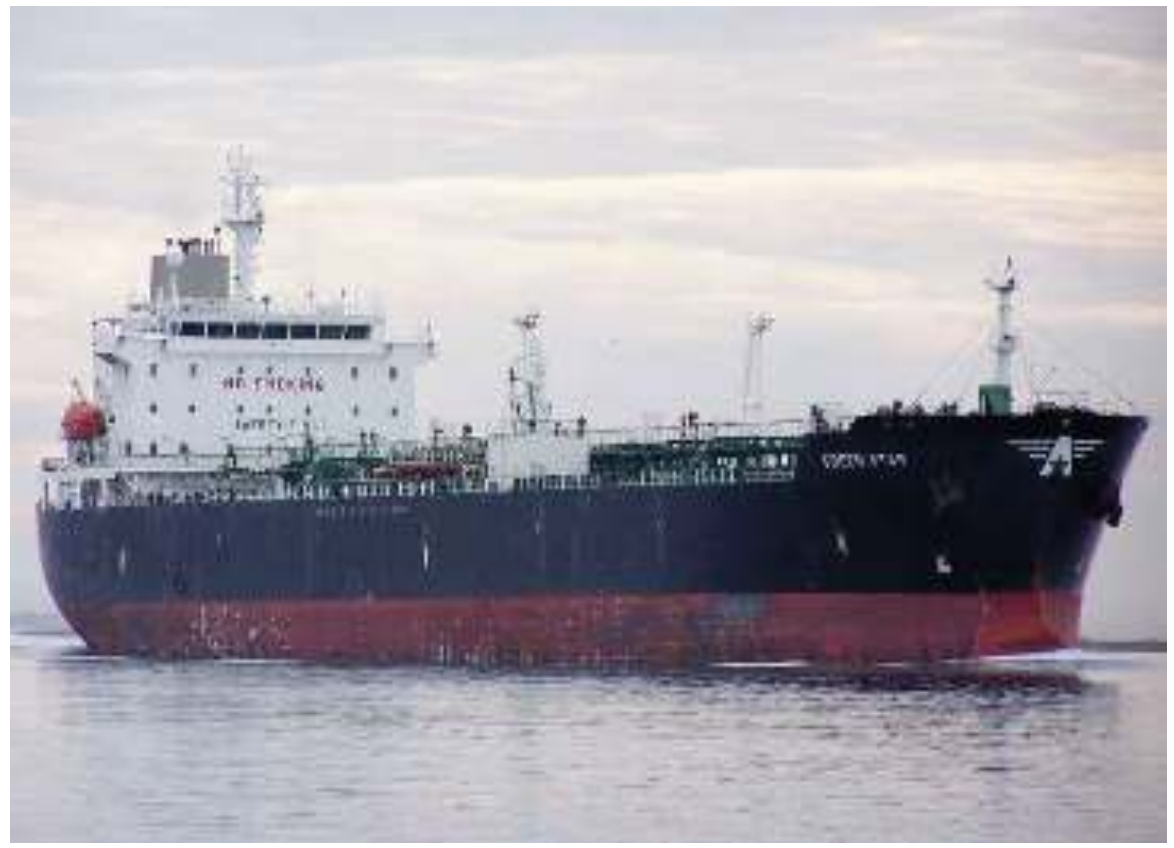

Gambar 1 : Lokasi Penelitian

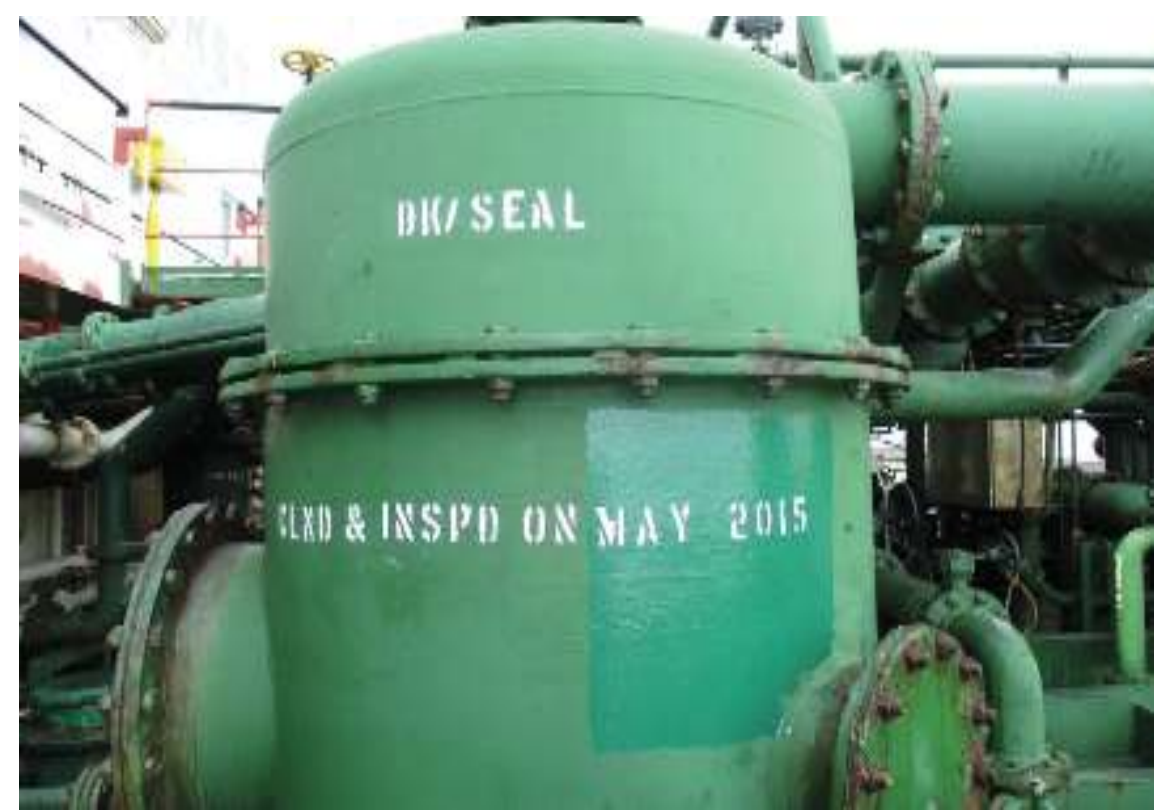

Gambar 2 : Deck Water Seal 


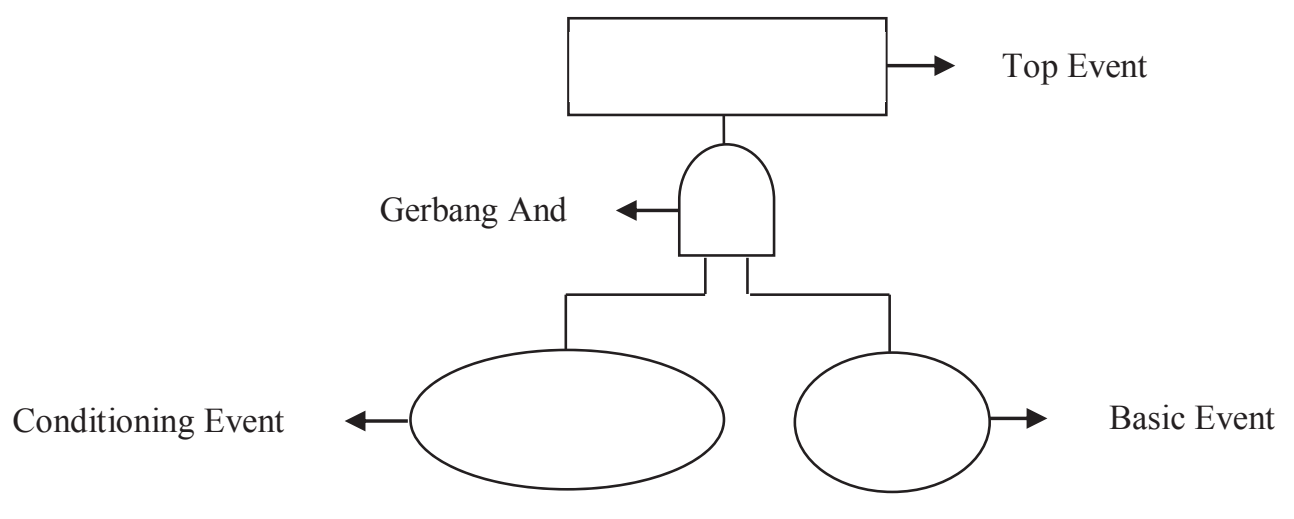

Gambar 3 : Kerangka diagram Fault Tree Analysis

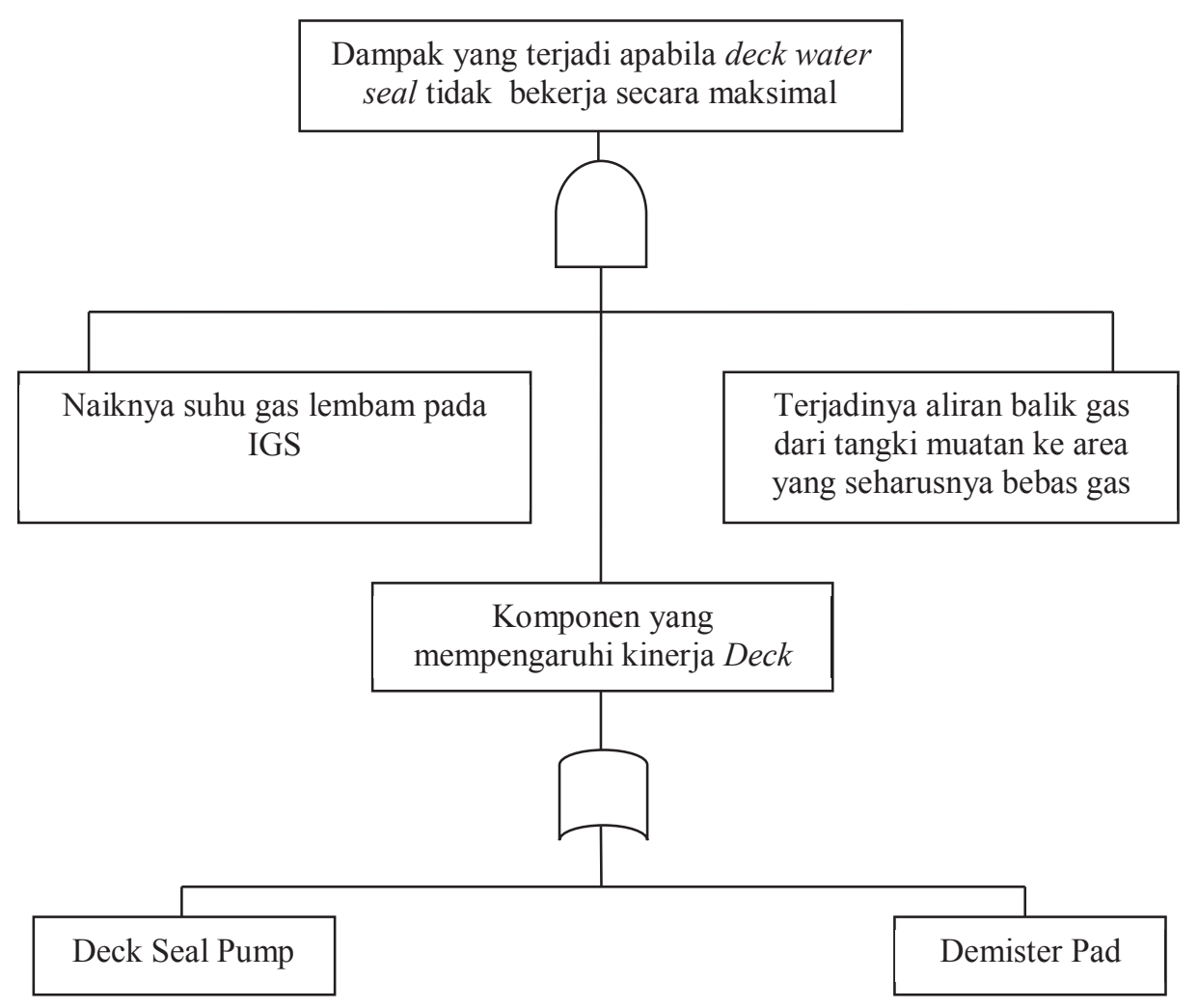

Gambar 4 : Penjabaran pohon kesalahan 